\title{
REDESIGN CORPORATE IDENTITY SEBAGAI PENINGKATAN IMAGE PERUSAHAAN STUDI KASUS PT. FINANSIA MULTI FINANCE
}

\author{
Ari Saputra ${ }^{1}$ \\ Ade Kosasih $^{2}$ \\ Deden Bagja Sudrajat ${ }^{3}$ \\ STMIK Raharja Jurusan Teknik Informatika ${ }^{1,2,3}$ \\ Jl. Jendral Sudirman No. 40, Modern Cikokol, Tangerang ${ }^{1,2,3}$ \\ Email: ari.saputra@raharja.info ${ }^{1)}$, adekosasih@raharja.info ${ }^{2)}$, deden.bagja@raharja.info ${ }^{3)}$
}

\begin{abstract}
ABSTRAK
Era globalisasi membawa dua dampak, di satu sisi dapat meningkatkan kesempatan di bidang ketenagakerjaan, di sisi lain terhadap dunia usaha kompetisi semakin tajam dan ketat. Oleh karena itu dibutuhkan strategi yang tepat dalam mencapai keberhasilan di bidang dunia usaha. Dalam memasarkan produk hingga saat ini perusahaan telah menggunakan berbagai bentuk media sarana penunjang diantaranya: media spanduk, xbanner, brosur, stiker produk dan didukung media visual lainnya yang digunakan perusahaan. Namun pihak perusahaan menyadari bahwa kompetitor dengan jenis usaha serupa semakin banyak dan juga terus berkembang. Permasalahan bertambah dengan adanya identitas logo yang lama belum sesuai dengan visi dan misi serta target management. Dari kondisi tersebut pihak perusahaan menghendaki adanya pembaharuan identitas perusahaan untuk membangun image dan identitas yang terbentuk lewat keseluruhan penampilan desain dalam setiap media promosi sebagai penunjang program promosinya agar lebih meningkatkan daya tarik kepada calon konsumen. Analisa permasalah didapat dari hasil wawancara dengan Branch Operation Manager PT. Finansia Multi Finance yang berkaitan dengan redesign perancangan corporite identity. Hasil akhir dari penelitian ini adalah pembuatan Grafik Standar Manual yang dimaksudkan agar pembuatan logo sebagai corporate identity suatu perusahan tersusun secara sistematis, dan tidak terjadi kesalahan persepsi atau pandangan di dalam penerapan logo pada setiap media yang ada diantaranya media spanduk, xbanner, brosur, stiker produk dan didukung media visual lainnya yang digunakan perusahaan. Dengan adanya redesign perancangan coorporite identity pada PT. Finansia Multi Finance, diharapkan dapat memperkuat eksistensi dan meningkatkan daya beli konsumen terhadap PT. Finansia Multi Finance itu sendiri.
\end{abstract}

Kata Kunci :Corporate identity, redesign, media promosi.

\section{ABSTRACT}

The era of globalization brings two effects, on the one hand can increase the opportunities in the field of employment, on the other side of the business world increasingly keen competition and tight. Therefore, it needs the right strategy for success in the business world. In marketing the product until now the company has been using various forms of media support facilities include: media banners, xbanner, brochures, stickers products and supported other visual media used by the company. But the company realized that a competitor with a similar type of business more and more, and also continues to grow. The problems increase with the identity of the old logo is not in accordance with the vision and mission as well as management targets. From the condition the company calls for the renewal of the corporate identity to build the image and identity is formed through the overall appearance of design in any media 
promotional campaign as a support program in order to further enhance the attractiveness to prospective customers. Analysis of problems derived from interviews with Branch Operation Manager PT. Finansia Multi Finance relating to the design of corporite identity redesign. The end result of this research is the manufacture of Graphic Standards Manual that is intended for the manufacture of the logo as a corporate identity of a company systematically arranged, and there is no error of perception / view in the application of the logo on any existing media include media banners, xbanner, brochures, stickers products and supported other visual media used by the company. With the redesign of the design coorporite identity at PT. Finansia Multi Finance, is expected to reinforce the existence and increase consumer purchasing power against PT. Finansia Multi Finance itself.

Keywords : Corporite identity, redesign, media promotion.

\section{PENDAHULUAN}

Dalam persaingan yang semakin ketat sebuah perusahaan memerlukan identitas yang solid. Identitas perusahaan yang sudah diciptakan agar dapat dikomunikasikan dalam setiap tampilan dan situasi secara terpadu, mudah dilihat dan dibaca, serta konsisten sehingga masyarakat luas menerima satu pesan yang selalu sama. Corporate identity adalah suatu bentuk visual dan ekspresi grafis dari image dan identitas suatu perusahaan. Sehingga dengan adanya corporate identity pada masing-masing perusahaan, akan membuat sebuah ciri khas tersendiri dari setiap perusahaan dan akan lebih mudah untuk diingat oleh masyarakat.

PT. Finansia Multi Finance atau yang lebih dikenal dengan nama Kredit Plus, memegang ijin usaha untuk menjalankan roda usaha pembiayaan, pajak, piutang dan kartu kredit yang tersebar di seluruh Indonesia. Untuk memasarkan produk tersebut hingga saat ini perusahaan telah menggunakan berbagai bentuk media sarana penunjang diantaranya: kartu nama, pin, pulpen, kalender, gelas, payung, shopping bag, jam dinding, stiker, dan $\mathrm{x}$ banner. Namun pihak perusahaan menyadari bahwa kompetitor dengan jenis usaha serupa semakin banyak dan juga terus berkembang, permasalahan utama adalah identitas logo yang lama belum sesuai dengan visi, misi, serta target management. Berdasarkan analisa yang dilakukan maka diperlukan New Comporate Identity.

Dari kondisi tersebut pihak perusahaan menghendaki adanya pembaruan identitas perusahaan untuk membangun image dan identitas yang terbentuk lewat keseluruhan penampilan desain dalam setiap media promosi sebagai penunjang program promosinya agar lebih meningkatkan daya tarik kepada calon konsumen.

Hasil akhir dari penelitian ini adalah pembuatan Grafik Standar Manual yang dimaksudkan agar pembuatan logo sebagai corporate identity suatu perusahan tersusun secara sistematis, dan tidak terjadi kesalahan persepsi atau pandangan di dalam penerapan logo pada setiap media yang ada. Hal ini sangat perlu diperhatikan untuk bisa membangun dan menjaga identitas perusahaan sesuai dengan citra, visi, dan misi perusahaan yang dikehendaki. Yang kemudian logo tersebut akan diimplementasikan ke semua media promosi nya antara lain seperti kartu nama, id card, kalender dan media visual lainnya yang digunakan perusahaan.

\section{PERMASALAHAN}

Untuk menyatukan pola berfikir dari berbagai pihak yang ingin memperoleh keuntungan lebih, dalam hal informasi di rasa perlu untuk berinteraksi dan berkomunikasi aktif dalam sebuah forum diskusi yang terdiri dari beberapa anggota, berkumpul ditempat dan 
waktu yang sama untuk saling bertatap muka dengan tujuan untuk berdiskusi memecahkan masalah, memberikan pendapat, hingga menemukan solusi yang tepat dan mudah dipahami dari topik pembahasan setiap forum diskusi. Adapun yang menjadi permasalahan adalah bagaimana menjadikan forum diskusi yang efektif dengan hasil diskusi yang maksimal tanpa harus mengalami kendala sebagai berikut :

Perlunya merancang sebuah desain agar dapat menunjukan identitas baru pada masyarakat bahwa PT. Finansia Multi Finance merupakan salah satu alternative perusahaan jasa pembiayaan yang memiliki keunggulan dibanding perusahaan lain yang ada di seluruh Indonesia.

Harus memerlukan berbagai bentuk media yang akan divisualisasikan sehubungan dengan adanya redesain corporate identity di PT. Finansia Multi Finance.

Dengan mengoreksi bagaimana caranya PT. Finansia Multi Finance untuk memaksimalkan media promosi yang ada guna meningkatkan minat dan daya beli masyarakat.

\section{LITERATURE REVIEW}

Berdasarkan studi pustaka yang dikumpulkan mengenai corporate identity. Maka literature review diperlukan untuk melihat penelitian-penelitian sebelumnya. Literature review yang ada adalah sebagai berikut:

1. Penelitian pertama dilakukan oleh Maryana Astuti dari Perguruan Tinggi Raharja pada tahun 2014 dangan judul "Redesign Visualisasi Logo Sebagai Identity Program di Divisi Raharja Enrichment Center". Penelitian ini menjelaskan tentang pentingnya identitas logo dalam suatu media visual lembaga institusi terhadap public, sehingga untuk mendukung hal tersebut dibutuhkan identitas logo untuk setiap program-program Raharja Enrichment Center yang dapat menarik dan dapat diimplementasikan sebagai identitas visual nya. Metode yang digunakan dalam penelitian ini adalah metode analisa perancanagan dengan dipergunakan aplikasi penunjang diantaranya aplikasi Adobe Illustrator CS5 sebagai pengolah rancangan objek-objek gambar vector, serta aplikasi Adobe Photoshop CS5 dipergunakan untuk mengolah gambar bitmap dengan konsep desain berisi mengenai perencanaan media. Dengan adanya identitas logo dari setiap program-program tersebut, publik akan mudah memahaminya dengan melihat sebuah tampilan yang konsisten dan mudah dikenali karena memiliki karakteristik khusus pada setiap program-programnya. Dari hasil rancangan identitas logo tersebut diharapkan untuk tahun-tahun berikutnya dapat memberikan suatu tampilan yang berbeda dan menarik dalam memperkenalkan programprogram Raharja Enrichment Centre tersebut.

2. Penelitian kedua selanjutnya dilakukan oleh Chyki Febrina dan R. Eka Rizkiantono dari Institut Teknologi Sepuluh Nopember (ITS) pada tahun 2013 dengan judul "Perancangan Identitas Visual Kampoeng Sepatu Sandal Krian sebagai Kampoeng Wisata Industri di Sidoarjo". Penelitian ini menjelaskan tentang central industri pengrajin sepatu Krian menjadi salah satu desa wisata industri yang ada di Sidoarjo, sehingga untuk mendukung hal tersebut, diperlukan identitas visual yang mengkomunikasikan Kampoeng Sepatu Sandal Krian sebagai kampoeng wisata industri. Pada proses perancangan identitas visual ini akan dibuat sebuah logo atau identitas mewakili visi dan misi kampoeng tersebut dengan konsep kreatif dan dinamis, Selain itu akan dibuat pula sebuah sistem grafis yang mendukung serta pengaplikasiannya pada media keperluan kampoeng, seperti stationery set, media marketing, merchandising, dan Envronmental Graphic Design.

3. Penelitian ke tiga dilakukan oleh Aat Ruchiat Nugraha dari Fakultas Ilmu Komunikasi Universitas Padjadjaran pada tahun 2007 dengan judul "Pengaruh Design Logo Baru 
BUMD yang Berbasiskan Kearifan Lokal Terhadap Citra Perusahaan" Penelitian ini dimaksudkan untuk mengetahui sejauh mana tampilan identitas logo baru PDAM Kota Bandung memberikan pengaruh terhadap citra perusahaan PDAM Kota Bandung di mata pelanggan yang ada di Kotamadya Bandung, dengan menggunakan variabel bebas penelitian syarat pembentukan logo yang efektif, yaitu: sifat unik logo, sifat fungsional logo, bentuk logo dan kemampuan logo dalam mempresentasikan perusahaan terhadap citra perusahaan PDAM Kota Bandung sebagai variabel terikatnya yaitu persepsi,kognisi, motivasi, dan sikap.

4. Penelitian ke empat diambil dari laporan Skripsi mahasiswa yang bernama Eva Fahrudin pada Perguruan Tinggi Raharja Jurusan Teknik Informatika Konsentrasi MAVIB tahun 2013/2014 dengan judul "Perancangan Madding Digital Berbasis Web Sebagai Media Informasi Sekolah Pada SMAN 8 Kabupaten Tangerang”. Media: Madding Digital. Penelitian ini mengambil tema tentang desain grafis untuk keperluan media promosi dan informasi dalam bentuk Madding Digital Berbasis web sebagai sarana penunjang media madding pada Sman 8 Kabupaten Tangerang.

5. Penelitian ke lima diambil dari International journal of innovative Reasearch in Management dengan penulis benama Kelli Tan Ai Li pada KBU Internasional Collelege, Selangor Darul Ehsan pada tahun 2013 dengan judul "How Does Logo Design Affect Consumers Brand Attitudes?". Penelitian ini membahas mengenai desain logo, Aspek visual logo dan sikap merek telah mendapat sedikit perhatian pada bagaimana mereka dapat digunakan untuk memperkuat persepsi merek di Malaysia. Tujuan dari penelitian ini adalah untuk mengeksplorasi peran komunikasi merek pada respon konsumen untuk desain logo di Malaysia. Sebanyak 90 responden di tiga lembaga pendidikan tinggi terkemuka berpartisipasi dalam studi. Sebuah rangsangan, analisis, regresi dan ANCOVA dilakukan dengan sikap merek terhadap logo yang dirancang sebagai variabel dependen. Variabel independen termasuk nilai-nilai merek, desain logo dan interaksi mereka. Temuan penelitian ini, dimaksudkan untuk memahami konsumen yang sangat berkomitmen untuk merek dan bagaimana desain logo pengaruh sikap merek. Peneltian ini juga menunjukan bahwa logo yang dipilih oleh konsumen mencerminkan tanggapan estetika mereka, sedangkan nama yang dipilih mencerminkan evaluasi mereka menawarkan merek atau kehadirannya dipasar. Untuk maksimum positif mempengaruhi dan meningkatkan ekuatan merek, disarankan agar desain logo yang rumit, alami dan harmonis karna ini dibuat positif mempengaruhi dan persepsi kualitas, makna khas, pengakuan mudah dan berbentuk desain feng shui. Selain itu, adalah penting bahwa untuk menyadari bahwa sikap merek dan desain logo dapat bermain sebagai peran penting sebagai nama perusahaan, dalam hal meyakinkan konsumen bahwa aka nada hubungan dengan pengalaman merek, dan menghorati merek-merek warisan.

Dari lima literature review yang ada, telah banyak penelitian mengenai Visualisasi Logo, Perancangan Identitas Visual, Desain Logo, Madding Digital Brbasis Web sebagai Media Informasi namun belum ada peneliti secara khusus membahas atau mengatasi masalah mengenai Redesign Corporate Identity sebagai Peningkatan Image Perusahaan Studi Kasus PT. Finansia Multi Finace. Kita membutuhkan perubahan corporate identity untuk menyegarkan identitas atau image perusahaan sehingga meningkatkan hubungan antar clien dan secara otomatis meningkatkan budget penjualan. 


\section{LANDASAN TEORI}

Menurut Iwan Binanto (2010 : 260-261) Perancangan adalah tahap pembuatan spesifikasi mengenai arsitektur program, gaya, tampilan, dan kebutuhan material atau bahan untuk program. Tahap ini biasanya menggunakan storyboard untuk menggambarkan deskripsi tiap scene lain dan bagan alur (flowchart) untuk menggambarkan aliran dari satu scene ke scene lain. Proses Perancangan Secara Umum menurut Hendi Hendratman (2010 : 09-12) terdiri dari persiapan data, Ide, Konsep, Media, Visualisasi dan Produksi. Selain Teori mengenai Perancangan, terdapat juga pengertian desain yang perlu diketahui. Menurut Rakhmat Supriyono (2010 : 136) Desain merupakan art direction, yaitu penampilan visual secara menyeluruh dari iklan. Hasil kerja sama antara art direction dan copywriter (berupa konsep verbal dan visual) dipadukan secara sinergis ke dalam desain melalui proses standar, yaitu membuat sketsa-sketsa kasar, menentukan alternatif desain, hingga final artwork (FAW). Pengertian lebih jelas mengenai Logo dapat disampaikan sebagai berikut. Menurut Ferri Caniago (2012 : 3) Logo merupakan suatu bentuk gambar atau sekedar sketsa dengan arti tertentu dan memiliki suatu arti dari perusahaan, daerah, perkumpulan, produk, negara dan hal-hal lainnya yang dianggap membutuhkan hal yang singkat dan mudah diingat sebagai pengganti dari nama sebenarnya.

\section{METODE PENELITIAN}

Didalam perolehan data lebih akurat dipenelitian ini, terdapat beberapa penerapan metode, yaitu : (1). Metode Analisa Permasalahan. Metode ini merupakan suatu metode yang digunakan untuk menentukan topik permasalahan penelitian, dalam hal ini dilakukan dengan bentuk interview yang menanyakan tentang permasalahan yang terdapat pada lembaga instansi yang terkait dengan penggunaan Identitas; (2). Metode Pengumpulan Data yaitu cara untuk mendapatkan data dengan jalan pengamatan secara langsung ke lokasi (Observasi), Interview ataupun dari kajian pustaka; (3). Metode Analisa Perancangan, dalam produksi Perancangan Identitas logo Sebagai Penunjang Informasi Divisi Raharja Enrichment Centre Pada Perguruan Tinggi Raharja dipergunakan aplikasi-aplikasi penunjang diantaranya aplikasi Adobe Illustrator CS5 sebagai pengolah rancangan objek-objek gambar vector, sedangkan aplikasi Adobe Photoshop CS5 dipergunakan untuk mengolah gambar bitmap; (4). Metode Analisa Perancangan, membuat sketsa-sketsa, menetukan alternative desain, hingga final $\operatorname{artwork}(F A W)$.

\section{PEMECAHAN MASALAH}

Dalam konsep perancangan corporate identity dan pengimplementasian media penunjang promosi pada PT. Finansia Multi Finance, bentuk media yang akan dirancang untuk penyempurnaan dan menambahkan media yang sudah digunakan adalah Grafik Standart Manual dan media yang akan dirancang antara lain adalah kartu nama, id card, amplop, map, kop surat, pin, pulpen, kalender, gelas, payung, shopping bag, jam dinding, seragam kerja marketing, stiker, flyer, mobil, x banner, gedung kantor cabang.

\section{Tujuan Media}

Tujuan dari perancangan media adalah sebagai salah satu sarana bentuk promosi sebagai identitas Finansia Multi Finance yang digunakan untuk mensosialisasikan kepada masyarakat mengenai kualitas dari produk pembiayaan yang ditawarkan oleh PT. Finansia Multi Finance yang selama ini telah terbangun. PT. Finansia Multi Finance selaku perusahaan yang bergerak dibidang jasa pembiayaan, sehingga masyarakat akan teringat pada PT. Finansia Multi Finance. 
Dari perancangan media diharapkan dapat menjangkau 75\% dari target yang diinginkan. Dengan media promosi yang terencana dengan baik, waktu dan lama promosi diharapkan tidak lagi menjadi masalah, media promosi yang dirancang untuk dapat tampil disegala kondisi, dengan demikian kontinuitas waktu promosi dapat berlangsung secara terus menerus tanpa bergantung pada momentum tertentu.

\section{Strategi Media}

Dalam program media perlu disampaikan yang diprogramkan sebagai media utama antara lain adalah kartu nama, id card, kop surat, seragam kerja marketing, dan flyer. Adapun yang diprogramkan menjadi media penunjangnya antara lain adalah amplop, map, pin, pulpen, kalender, $x$ banner. Dan media pendukungnya antara lain adalah gelas, payung, shopping bag, jam, stiker, mobil, dan gedung kantor cabang. Dari dua kategori media tersebut diharapkan dapat meningkatkan minta konsumen untuk melakukan transaksi di PT. Finansia Multi Finance untuk waktu-waktu berikutnya. Adapun aspek sasaran media yang akan dirancang adalah:

Geografi
Demografi
- Jenis Kelamin
- Usia
- Kelas Ekonomi
- Sasaran
Psikogaf

Geografi

- Jenis Kelamin

- Sasaran

Psikogaf
: Kota-kota besar di seluruh wilayah Indonesia

: Pria dan Wanita

$: 21 \mathrm{~s} / \mathrm{d} 60$ thn

: Menengah kebawah

: Masyarakat

: Masyarakat yang membutuhkan produk pembiayaan untuk berbagai hal seperti modal wirausaha, biaya kesehatan, biaya pendidikan, dan lain-lain.

\section{Perencanaan Pesan (Konsep Kreatif)}

Agar perancangan redesign corporate identity dan pesan program promosi dapat mendapatkan perhatian kalangan masyarakat, strategi pesan yang digunakan adalah: Pesan promosi penjualan produk disampaikan melalui bentuk gambar dan teks dengan penataan Layout kreatif sesuai kebutuhan media yang diinginkan. Dari bentuk gambar dan teks tersebut diharapkan selain menarik perhatian secara visual, pesan tujuan penawaran produk mudah dimengerti dan dipahami. Dengan isi pesan tersebut cepat mendapatkan perhatian berarti pesan akan efektif sampai ke calon konsumen.

\section{Perencanaan Visual (Konsep Visual)}

Berikut disampaikan penjelasan mengenai perencanaan visual yang terdapat: Penjelasan tujuan visual, strategi visual, penulisan naskah, pengarahan visualisasi dan proses desain:

\section{Tujuan Visual (Visual Objective)}

Sesuai dengan citra PT. Finansia Multi Finance yang selama ini telah terbentuk, yakni sebagai perusahaan pembiayaan yang memilki kecepatan dalam pelayanan, maka perancangan visual yang dibentuk dalam setiap desainnya diharapkan dapat memberikan kesan atau tampilan yang dapat mewakili pencitraan PT. Finansia Multi Finance terhadap masyarakat. Setiap rancangan media bernuansakan cerminan produk yang akan dipasarkan oleh Finansia Multi Finance. 


\section{Strategi Visual (Visual Strategy)}

Dalam setiap perancangan yang dibuat, digunakan image atau objek yang dapat mewakili nuansa citra produk yang dipasarkan oleh PT. Finansia Muliti Finance. Penyajiannya, menggunakan pendekatan secara emosional, dimana tampilan yang berupa gambar atau teks yang memberi kesan dan penjelasan mengenai fungsi dan kegunaan dari setiap produk yang ingin dipasarkan.

Setiap media yang dirancang tidak meninggalkan pencitraan atau image PT. Finansia Multi Finance yang selama ini sudah terbentuk. Sedangkan untuk gaya penyajian grafisnya berkesan modern yang simple dan elegan, serta cara penyampaian yang berkesan tegas dengan slogan-slogan yang menjadi ciri khas perusahaan.

\section{Penulisan Naskah (Copy Writing)}

Dalam setiap perancangan desain, terdapat unsur-unsur komunikasi grafis, yakni teks (tulisan), Ilustrasi (gambar, foto) dan warna. Berikut adalah penjabaran dari bagian-bagian teks (tulisan) :

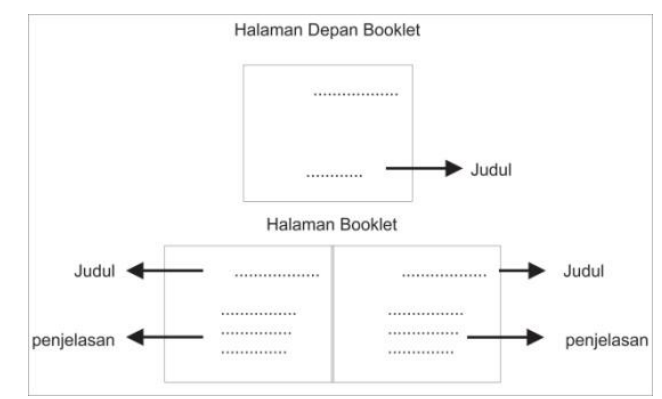

Gambar 1 : Keterangan Penulisan Naskah

1. Judul (Head Line)

Media rancangan Spanduk disampaikan bentuk Head Line: Lebih cenderung ke Nama Produk

2. Sub Judul (Sub Headline)

Selanjutnya Sub Headline disampaikan mengenai ajakan ataupun anjuran yang berkenaan dengan manfaat dari produk.

3. Logo

Logo adalah identitas produk dan identitas perusahaan yang menunjukkan cerminan dari produk yang akan dipasarkan oleh perusahaan.

4. Slogan

Slogan adalah kalimat pendek yang menarik dan mudah diingat untuk memberitahukan atau menyampaikan sesuatu.

\section{Pengarahan Visualisasi (Art Directing)}

Dalam pembuatan media seperti desain spanduk, desain shopping bag, desain xbanner, desain poster, desain memo, desain brosur, desain kartu nama, desain map, desain stiker, agar desain tersebut terlihat menarik dan memiliki karakter.

1. Warna yang dipilih adalah :

a. Warna Orange

Warna orange memberi kesan hangat dan bersemangat. Warna ini merupakan symbol dari petualangan, optimisme, percaya diri dan kemampuan dalam bersosialisasi. Sama 
halnya dengan PT. Finansia Multi Finance yang selalu bersemagat untuk terus memberikan pelayanan terbaiknya kepada masyarakat.

b. Warna Biru

Diyakini bahwa warna biru dapat merangsang kemampuan berkomunikasi, ekspresi artistic dan juga sebagai symbol kekuatan. Berdasarkan cara pandang ilmu psikologi warna biru tua mampu merangsang pemikiran yang jernih dan biru muda membantu menenangkan pikiran dan meningkatkan konsentrasi. PT. Finansia Multi Finance percaya bahwa komunikasi adalah jembatan utama untuk membangun sebuah kesuksesan dalam dunia bisnis.

c. Warna Putih

Warna suci dan bersih, natural, kosong, tak berwarna, netral, awal baru, dan kesederhanaan. Sesuai dengan salah satu nilai yang tertanam dalam budaya PT. Finansia Multi Finance bahwa segala sesuatu harus berawal dari kesederhaan.

d. Warna Hitam

Sebagai warna kemasan, hitam melambangakan keanggunan (elegance), kemakmuran (wealth) dan kecanggihan (sopiscated). menunjukkan hal yang tegas, elegan, dan eksklusif.

2. Jenis huruf yang digunakan adalah:
a. Logo Utama
b. Tagline "Belanja Nyaman Tanpa Tunai"
: Air Millhouse Italic
d. Judul Cover Grafis Standar Manual : Aller Regular
e. Isi buku Grafis Standar Manual : Roboto (Light)
f. Penomoran halaman
g. Media visualisasi
: Aller Regular
: Swis721 Lt BT

3. Tata letak atau Layout yang digunakan adalah:

Tata letak disesuaikan dengan menempatkan unsur-unsur desain yang terdiri dari logo PT. Finansia Multi Finance, slogan-slogan, testimonial, gambar elektronik, gambar produk, serta alamat dengan menggunakan susunan horizontal.

4. Gaya penampilan grafis adalah:

Gaya tampilan visual secara grafis ditampilkan secara Simple dan Elegant serta keseragaman antar elemen tiap media komunikasi grafis, dimaksudkan agar relasi perusahaan, masyarakat dan relasi pemerintahan dapat lebih mudah mengetahui pesan media dan ciri khas yang ditampilkan sebagai penunjang promosi.

5. Model yang dipilih adalah:

Dalam penggunaan model, dibuat lebih fleksibel namun tetap pada aturan yang telah ditetapkan oleh Finansia Multi Finance sebagai acuan identitas PT. Finansia Multi Finance seperti penggunaan gambar dan slogan-slogan.

\section{IMPLEMENTASI}

Proses Desain (Designing)

Untuk mendapatkan kesempurnaan pada hasil akhir. Dalam hal ini perencanaan yang teratur untuk mencapai kesempurnaan sangat penting untuk diperhatikan. Dalam pelaksanaan tahapan desain yang baik harus memiliki 3 (tiga) tahapan proses, yaitu: 
1. Layout Kasar

2. Layout Komprehensif

3. Final Art Work

Berikut penjabaran dari pelaksanaan 3 (tiga) tahapan proses desain:

1. Layout Kasar

Layout kasar merupakan gambaran kerja untuk memperlihatkan komposisi tata letak naskah, gambar yang akan dibuat, biasanya pada Layout kasar dibuat hitam putih, berupa coretan kasar atau sketsa dengan menggunakan pensil gambar yang dibuat secara manual. a. Layout Kasar Buku Grafik Standar Manual.
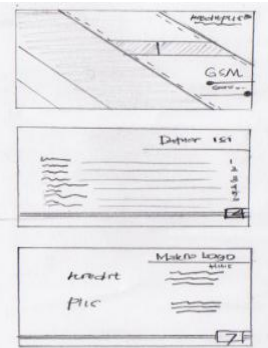

Gambar 2 : Layout Kasar Buku Grafik Standar Manual
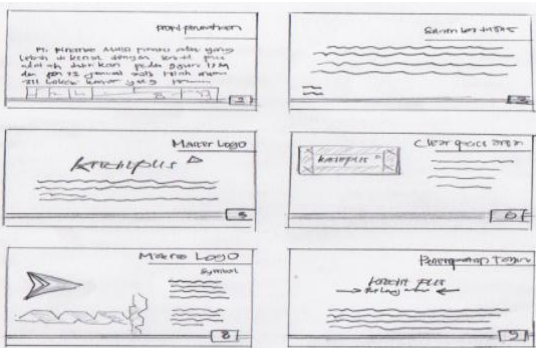

$\rightarrow$ toment Ex

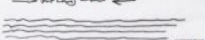

b. Layout Kasar Media Kartu Nama

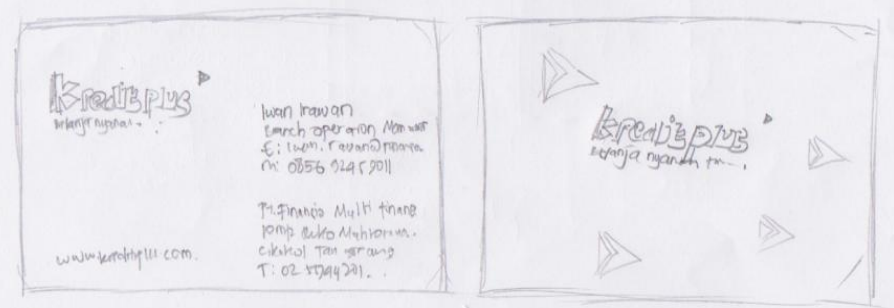

Gambar 3 : Layout Kasar Media Kartu Nama

c. Layout Kasar Media Id Card

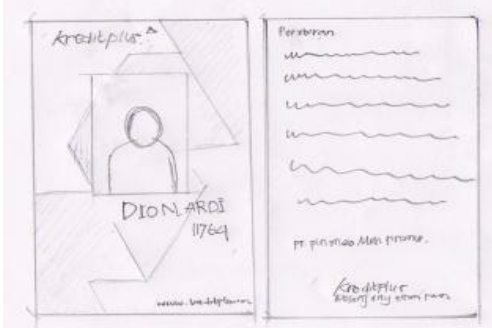

Gambar 4 : Layout Kasar Media Id Card

d. Layout Kasar Media Kalender
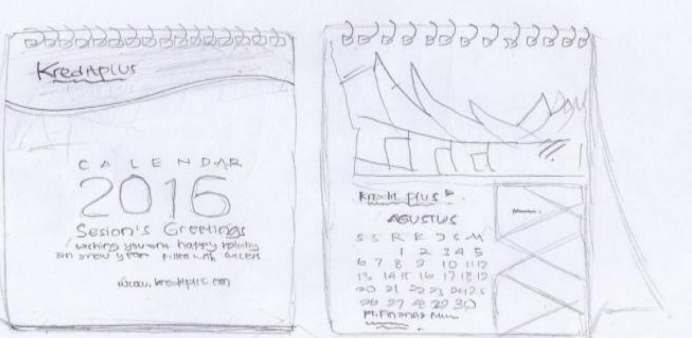

Gambar 5 : Layout Kasar Media Kalender 


\section{e. Layout Kasar Media Stiker Mobil}

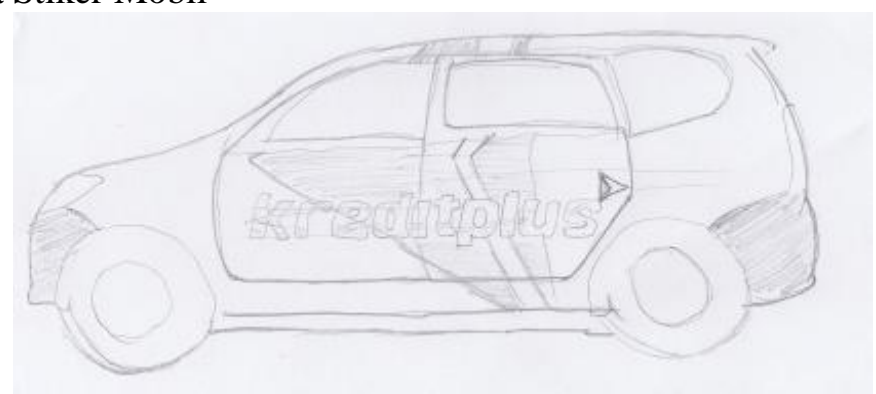

Gambar 6 : Layout Kasar Media Stiker Mobil

2. Layout Komprehensif

Layout komprehensif adalah suatu gambar yang sudah mendekati komposisi Final, dalam hal ini komposisi gambar yang pada umumnya disajikan dalam bentuk warna.

a. Layout komprehensif grafik standar manual

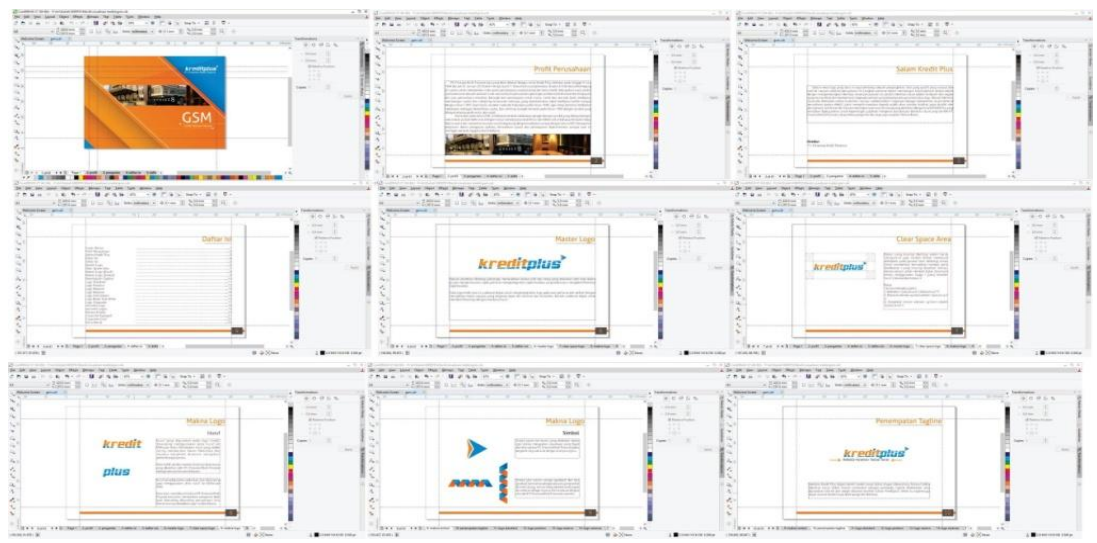

Gambar 7 : Layout Komprehensif Buku Grafis Standar Manual

Deskripsi

Nama : Buku Grafis Standar Manual

Media : Art carton 260 gram dan Art paper 210gr

Material : $21 \mathrm{~cm} \mathrm{x} 29,7 \mathrm{~cm}$

Ukuran : Full Color

Warna : Di kantor PT. Finansia Multi Finance sebagai acuan dan dan standar Alokasi penggunaan logo pada berbagai media sebagai corporate identity pada PT. Finansia Multi Finance.

b. Layout komprehensif media kartu nama

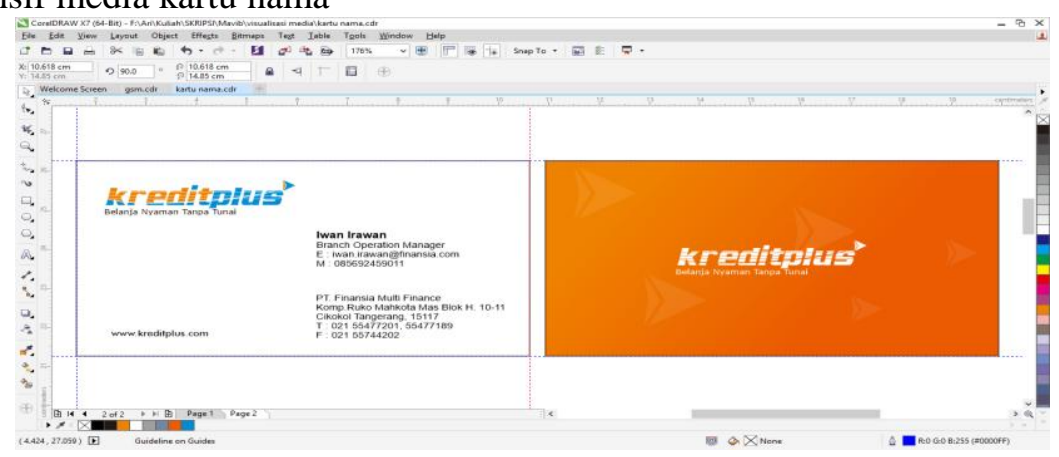

Gambar 8 : Layout Komprehensif Media Kartu Nama 
$\underline{\text { Deskripsi }}$

Nama

Media

Material

Ukuran

Warna

Alokasi

Kartu Nama

Art Carton 260gr

$9 \mathrm{~cm} \times 5 \mathrm{~cm}$

Orange, biru, hitam, putih

Karyawan PT. Finansia Mult Finance pada jabatan manager, marketing, dan collector.

c. Layout komprehensif media id card

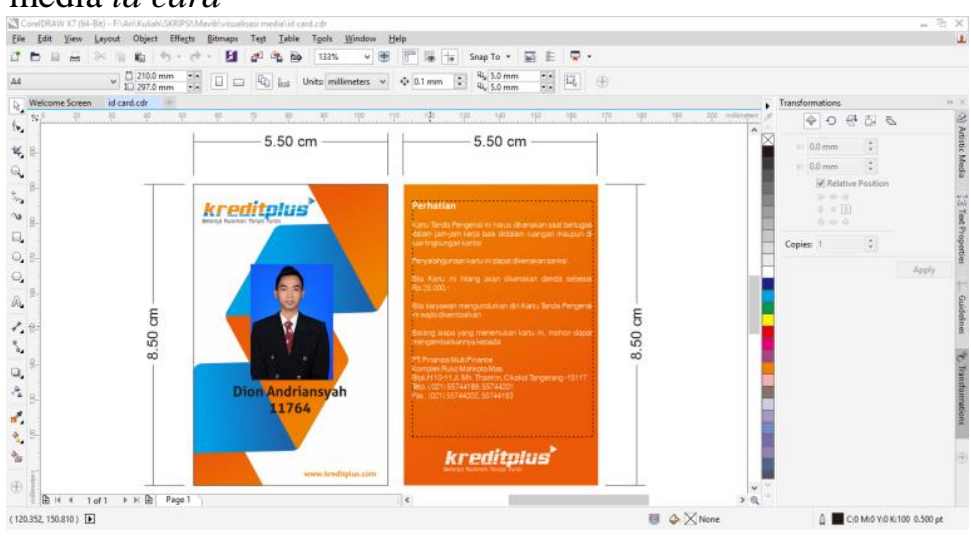

Deskripsi

Gambar 9 : Layout Komprehensif Media Id Card

Nama Media : Id Card

Material : Instant PVC

Ukuran $\quad: \quad 5.5 \mathrm{~cm} \times 8.5 \mathrm{~cm}$

Warna : Orange, biru, hitam, putih

Alokasi : Seluruh karyawan PT. Finansia Mult Finance.

d. Layout komprehensif media kalender

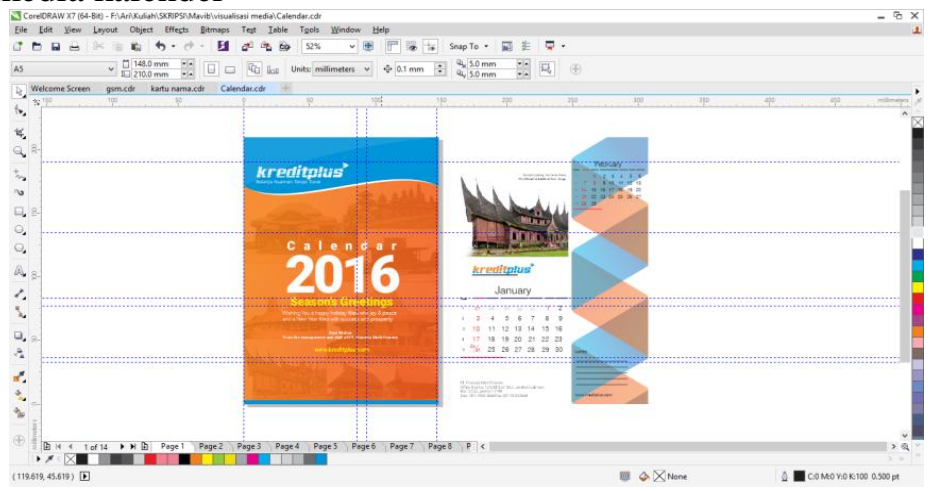

Gambar 10 : Layout Komprehensif Media Kalender

Deskripsi

Nama : Kalender

Media : Art Paper $150 \mathrm{gr}$, dan Ivory $230 \mathrm{gr}$

Material : $18 \mathrm{~cm} \mathrm{x} 12 \mathrm{~cm}$

Ukuran : Orange, biru, putih, kuning, hitam

Warna : Seluruh karyawan serta digunakan di perusahaan sebagai media promosi

Alokasi kepada konsumen yang melakukan transaksi di PT. Finansia Multi Finance. 
e. Layout komprehensif media stiker mobil

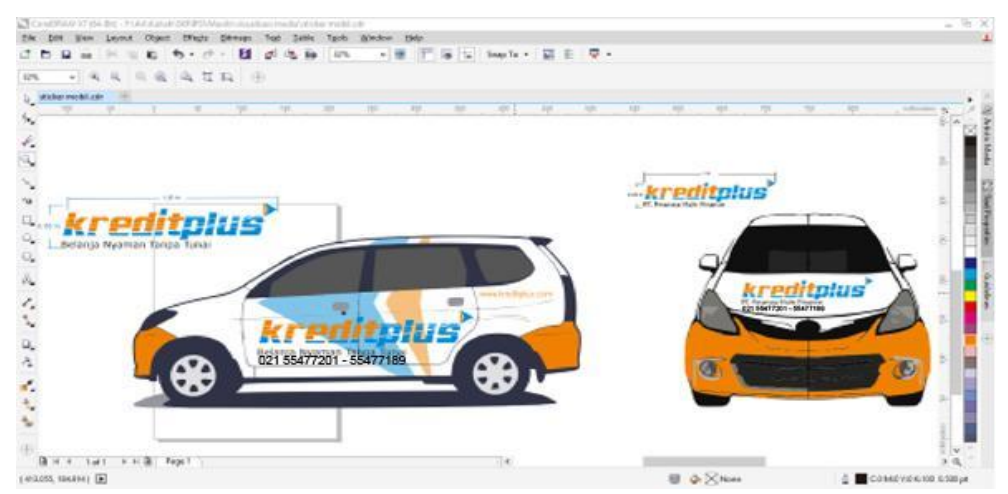

Gambar 11 : Layout Komprehensif Media Stiker Mobil

$\underline{\text { Deskripsi }}$

Nama Media

Material

Ukuran

Warna

Alokasi

: Stiker Mobil

: Oracal 651 series Intermediate Cal

: $180 \mathrm{~cm}$ x $50 \mathrm{~cm}, 100 \mathrm{~cm}$ x $20 \mathrm{~cm}, 160 \mathrm{~cm}$ x $50 \mathrm{~cm}$

: Orange, biru, dan hitam

: Digunakan oleh marketing untuk memasarkan produk perusahaan.

\section{Final Art Work}

Adalah tahap akhir dimana keseluruhan unsur-unsur sudah tersusun dengan baik dan siap untuk dicetak (dipublikasikan).

a. Layout Final Art Work Buku Grafis Standar Manual
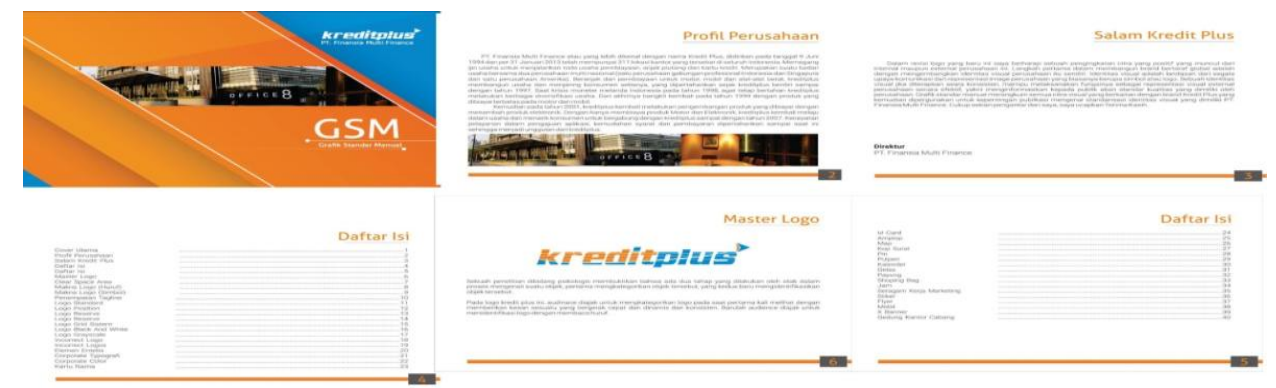

Krealitplats
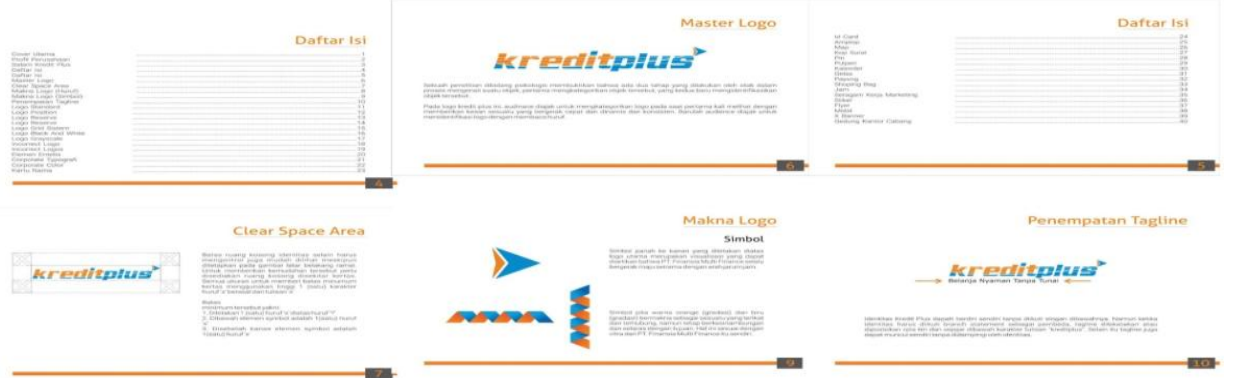

Gambar 12 : Layout Final Art Work Buku Grafis Standar Manual

b. Layout Final Art Work media kartu nama

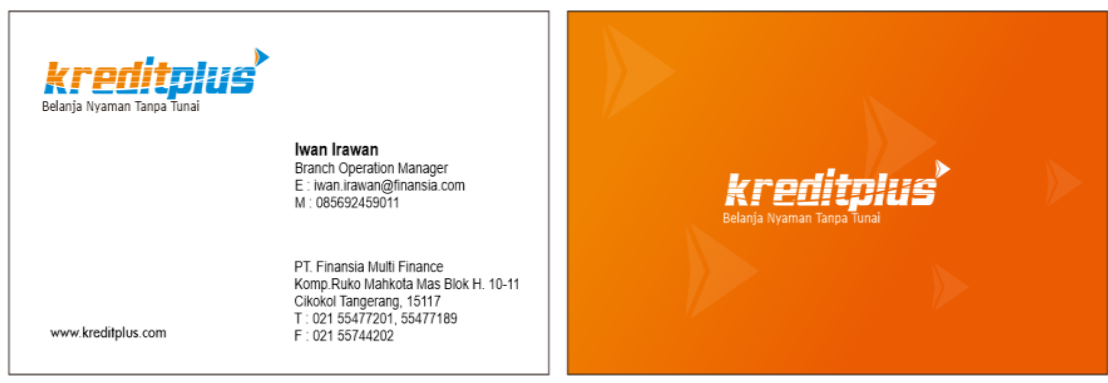

Gambar 13 : Layout Final Art Work Media Kartu Nama 
c. Layout Final Art Work media id card
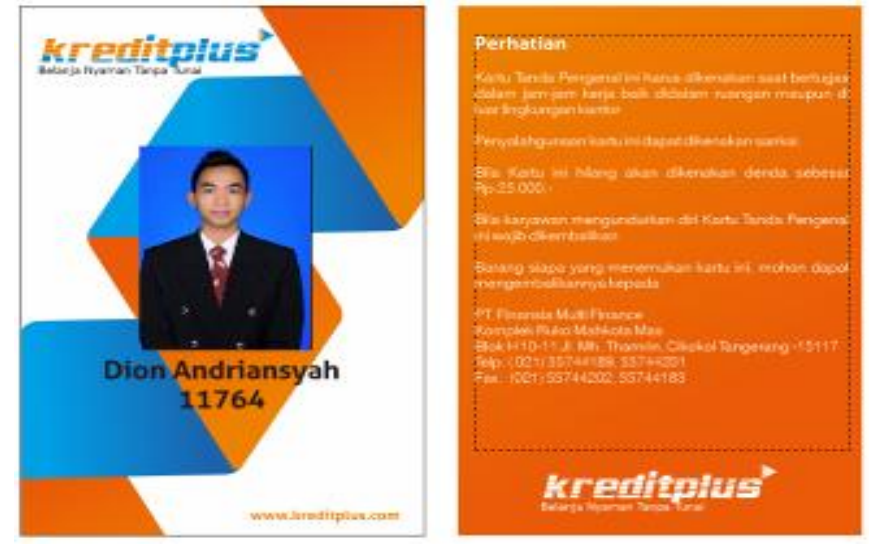

Gambar 14 : Layout Final Art Work Media Id Card

d. Layout Final Art Work media kalender

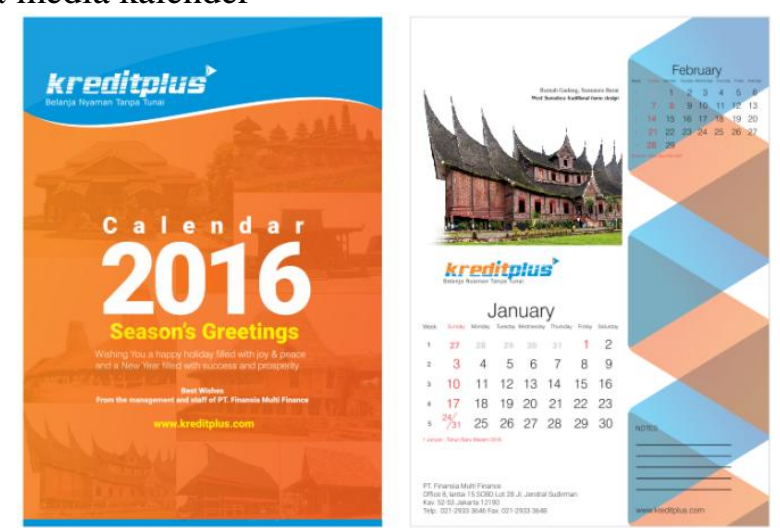

Gambar 15 : Layout Final Art Work Media Kalender

e. Layout Final Art Work media stiker mobil
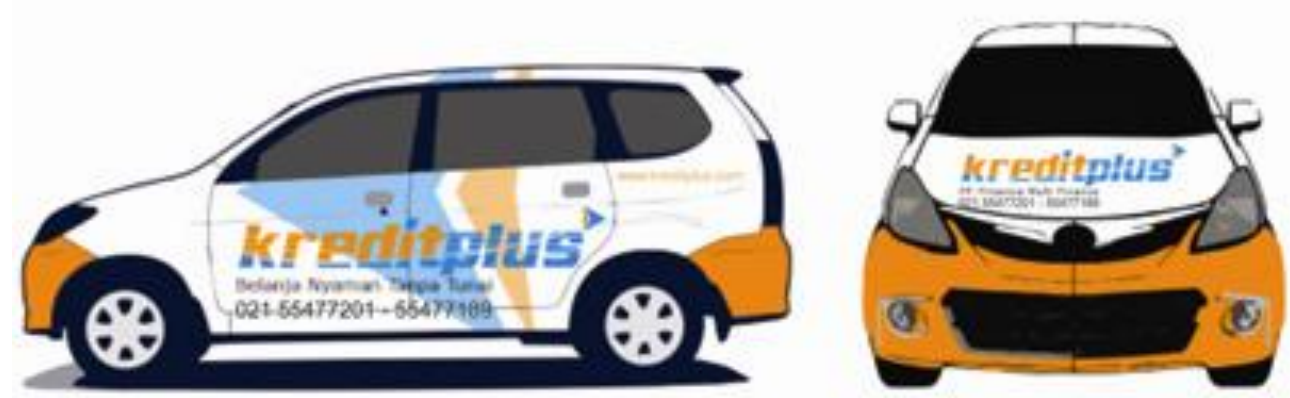

Gambar 16 : Layout Final Art Work Media Stiker Mobil

\section{Kelebihan}

Dengan New Corporate Identity, perusahaan dapat memaksimalkan media promosi sesuai dengan image perusahaan dengan visi, misi, serta target yang telah ditetapkan perusahaan sehingga jalanya identitas perusahaan dengan promosi sesuai yang diharapkan.

Beberapa kelebihan dari New Corporate Identity ini adalah sebagai berikut : Identitas yang jelas, image yang baik, meningkatkan kinerja perusahaan, kebanggan perusahaan, dan jaringan yang baik. 


\section{Kekurangan}

Keterbatasan utamanya ialah perusahaan harus mensosialisasikan kembali New Comporate Identity dan image yang sudah ada agar masyarakat dapat mengenal kembali Comporate Identity yang baru. Namun dengan keterbatasan ini corporate identity tetap menjadi media promosi yang baik dalam merefreshing Image perusaahaan dan membentuk media promosi yang lebih baru serta menarik.

\section{KESIMPULAN}

Logo bisa dikatakan sebuah lambang ataupun ciri untuk memudahkan pengenalan sebuah perusahaan dan juga corporate identity atau identitas perusahaan yang mewakili citra perusahaan. Dengan demikian bagi suatu perusahaan logo merupakan cerminan dari nilai-nilai ideal tujuan perusahaan, yang meliputi aspek visi dan misi, ruang lingkup kerja, serta budaya perusahaan. Logo merupakan representasi dari ide-ide yang abstrak menjadi sesuatu yang nyata, dan berperan sebagai wajah dari institusi tersebut. Sebagai bahasa penanda, biasanya logo ditampilkan berupa simbol yang mencerminkan citra tertentu yang sengaja dibangun oleh suatu institusi, perusahaan atau lembaga.

Perubahan logo tidak serta merta dilakukan bukan tanpa alasan namun dengan tujuan ingin meningkatkan image baik lagi terhadap masyarakat dan juga diikuti dengan meningkatkan kinerja perusahaan serta menerapkan program - program baru untuk masyarakat.

Dalam merancangan sebuah desain identitas baru perusahaan kepada masyarakat dapat dilakukan dengan menciptakan sebuah identitas visual logo perusahaan yang memiliki komposisi warna, dan struktur logo yang bersifat dinamis, modern, namun tetap berpegang kepada visi dan misi serta target PT. Finansia Multi Finance.

Media promosi yang ada dapat dimaksimalkan penggunaanya dengan meningkatkan kegiatan promosi seperti penyebaran flyer, pemasangan $x$ banner di setiap stand kredit plus, dan pemberian merchandise ke pada konsumen yang hendak melakukan repeat order.

\section{DAFTAR PUSTAKA}

[1] Budi Permana dan Kurweni Uker, Adobe Photoshop, Yogyakarta: Andi Offset, 2010.

[2] Dewi Immaniar Desrianti, Sudaryono, Dwi Ayu Ningrum, Enriching Media Merchandise.

[3] Dewi Immaniar, Anita B Wandanaya, Asih Sumaryani, Perancangan Media Katalog Sebagai Penunjang Informasi Dan Promosi Pada CV. ZERO STORE, Journal CCIT Vol. 7 No.2 Desember 2013. Tangerang: Perguruan Tinggi Raharja, 2013.

[4] Dewi Immaniar, Untung Rahardja, Reni Mulyani, Audio Visual As One Of The Teaching Resources On Ilearning, Jurnal CCIT Vol. 5. No.2, 2012

[5] Hendratman, Hendi. Tips N Trik Computer Grapics Design, Bandung: Informatika Bandung, 2009.

[6] Indriyani, Evi. Humdiana. Sistem Informasi Manajemen, Mempersiapkan Pekerja Berbasis Pengetahuan Dalam Mengelola Sistem Informasi, Jakarta: Mitra Wacana Media, 2010.

[7] Jerry Fitz Gerald, Andra F. Fitz Gerald, Warren D. Stallings, Jr, Fundamentals of System Analysis yang diterjemahkan oleh Jogiyanto HM, 2010.

[8] Jogiyanto, Sistem Informasi Teknologi, Andi Offset, 2010. 
[9] Jogiyanto, Analisis Dan Desain Sistem Informasi, Yogyakarta: Andi Offset, 2010. Kusrini, Strategi Perancangan Dan Pengelolaan Basis Data, Yogyakarta: Andi Offside, 2010.

[10] Liliweri, Alo. Komunikasi Serba Ada Serba Makna, Jakarta: Prenada Media Group, 2011.

[11] Madcoms, Kreasi Desain Kaos Distro dengan Coreldraw untuk Pemula Expression Of Love, Andi, 2011..

[12] Marketing Communications, PT. Gramedia pustaka, 2009.

[13] Mulyanto, Agus, Sistem informasi konsep dan aplikasi atau PPL, Pustaka Pelajar, Yogyakarta, 2009.

[14] Nugroho,Eko. Sistem Informasi Manajemen, Yogyakarta: Andi Offset, 2010.

[15] O'Brien dalam bukunya Yakub, Pengantar Sistem Informasi. Yogyakarta : Graha Ilmu, 2012.

[16] Pujiriyanto, Desain Grafis Komputer, Yogyakarta: Andi, 2009.

[17] Rangkuti, Freddy, Strategi Promosi yang Kreatif dan Analisis Kasus Integrated Sarana Penunjang Promosi Studi Kasus Pada BookStore. dalam jurnal CCIT vol. 7, No.3, 2014.

[18] Sunarya, Lusyani, S.Sn., pada Diktat Mata Kuliah Desain Karakter And Modeling, 2010.

[19] Supriyono, Rakhmat. Desain Komunikasi Visual Teori dan Aplikasi, Yogyakarta : Andi, 2010.

[20] Rustan, Surianto, Mendesain Logo, Jakarta : Gramedia Pustaka Utama, 2009.

[21] Tjiptono, Fandy. Strategi Pemasaran, Yogyakarta: Andi, 2009.

[22] Widada, Sugeng, Diktat Mata Kuliah Aplikasi Program Komputer Mavib 1, Tangerang: Perguruan Tinggi Raharja, 2010.

[23] Widada, Sugeng. Diktat Mata Kuliah Nirmana, Tangerang: Perguruan Tinggi Raharja, 2010. 